УДК 342.5

DOI 10.18413/2712-746X-2020-45-1-133-140

\title{
НЕКОТОРЫЕ ПРОБЛЕМЫ «РЕГУЛЯТОРНОЙ ГИЛЬОТИНЫ»
}

\section{SOME PROBLEMS OF THE «REGULATORY GUILLOTINE»}

\author{
О.И. Чепунов \\ O.I. Chepunov
}

\author{
Российская академия народного хозяйства и государственной службы \\ при Президенте Российской Федерации, \\ Россия, 119571, г. Москва, проспект Вернадского, 82, стр.1 \\ Russian Presidential Academy of National Economy and Public Administration, \\ 82 Vernadskogo Ave., Moscow, 119571, Russia \\ E-mail: chepunovoleg@yandex.ru
}

\begin{abstract}
Аннотация
Реформирование государственного регулирования контрольно-надзорной деятельности, связанной с нарушением обязательных требований нормативных правовых актов, относится к одной из наиболее активно обсуждаемых тем как среди экспертного сообщества, так и среди представителей бизнеса и контрольно-надзорных органов. Автором рассмотрен механизм «регуляторной гильотины» при создании в сферах регулирования контрольно-надзорной деятельности новой системы понятных и четких требований к контрольно-надзорным органам и хозяйствующим субъектам с целью ликвидации избыточных административных требований, снижения уровня нагрузки и рисков причинения вреда (ущерба) субъектам экономических отношений и охраняемым общественным ценностям. Представлен зарубежный опыт применения регуляторной гильотины, элементы которого возможно применить в отечественной реформе государственного контроля и надзора. Уделено внимание рискам эффективной реализации механизма «регуляторной гильотины», в числе которых коррупция в органах государственной власти и местного самоуправления. Успешность процесса реализации контрольно-надзорной реформы автор связывает со способностями экспертного сообщества, рабочих групп и регулятивных органов обеспечить качественное и оперативное выполнение поставленных задач под руководством Министерства юстиции Российской Федерации.
\end{abstract}

\begin{abstract}
Reforming state regulation of control and supervision activities related to the violation of mandatory requirements of regulatory legal acts is one of the most actively discussed topics, both among the expert community and among representatives of business and regulatory authorities. Repeated attempts to optimize state control (supervision), reduce administrative barriers associated with it, and reduce excessive interference in the activities of business entities did not achieve the desired results, including due to insufficient attention and ambiguous understanding of the expected result of control and supervision activities, the compromise nature of decisions. One of the reasons for the low efficiency of past initiatives is the redundancy of mandatory requirements in regulatory legal acts regulating the function of control and supervision. The article considers the mechanism of the regulatory guillotine. It is used when creating a «new» system of clear and clear requirements for control and Supervisory authorities and business entities in the areas of regulation of control and supervision activities. The purpose of this mechanism is to eliminate excessive administrative requirements, reduce the level of load and risk of causing harm (damage) to the subjects of economic relations and protected public values. The author presents the foreign experience of using the regulatory guillotine, elements of which can be applied in the domestic reform of state control and supervision. Attention is paid to the risks of effective implementation of the «regulatory guillotine» mechanism, including corruption in state and local authorities. The author attributes the success of the process of implementing the control and supervision reform to the ability of the expert community, working groups and regulatory bodies to ensure high-
\end{abstract}


quality and prompt implementation of the tasks set under the leadership of the Ministry of justice of the Russian Federation.

Ключевые слова: регулятивная гильотина, система, требования, рабочие группы, хозяйствующие субъекты, органы государственной власти.

Keywords: regulatory guillotine, system, requirements, working groups, business entities, public authorities.

\section{Введение}

В любом государстве, в том числе и в России, периодически возникают проблемы пересмотра перечня действующих правовых актов, содержащих обязательные требования, соблюдение которых оценивается при проведении мероприятий по государственному контролю и надзору. Если в системе государственного управления нет постоянно действующего институционального механизма модернизации контрольно-надзорной системы, то через определенное время сложность и объем регулирования существенно возрастут вследствие противоречивости постоянно увеличивающихся норм данного института. Этот негативный процесс государственной контрольно-надзорной деятельности на всех властных этажах государственного аппарата многократно усугубляется высоким уровнем бюрократических процедур и системной коррупцией. Попытки внедрения антибюрократического и антикоррупционного «нового» наталкиваются на действующее и не желающее меняться «старое». Вследствие этого образуются глубокие системные противоречия в контрольно-надзорной деятельности, усугубляющие кризисные явления в государственном управлении. Все это негативно отражается на политико-правовых и экономикосоциальных процессах позитивного государственного управления.

Для преодоления кризисных явлений появляется насущная необходимость создавать в сферах регулирования контрольно-надзорной деятельности «новую» систему понятных и четких требований как к контрольно-надзорным органам, так и к хозяйствующим субъектам для ликвидации избыточных административных требований, снижения уровня нагрузки и рисков причинения вреда (ущерба) субъектам экономических отношений и охраняемым общественным ценностям.

В отечественную юридическую науку исследованию проблем реформ в сферах регулирования контрольно-надзорной деятельности исследовали Р.Н. Аганина, Т.А Андронова [Аганина, Андронова, 2020], О.В. Александров [2019], Ю.Г Арзамасов [2013], А.А. Кармолицкий [2014], А.В. Кнутов [2015], Ю. Любимов [Любимов, Новак и др., 2019], С.В. Семенов и А.В. Чаплинский [2014], И.Ю. Синдеева [2014], С. Щербатова [2019] и другие.

Анализ научных исследований в сферах регулирования контрольно-надзорной деятельности указывает на то, что существует необходимость обоснования системы понятных и четких требований к контрольно-надзорным органам и хозяйствующим субъектам с целью ликвидации избыточных административных требований, снижения уровня нагрузки и рисков причинения вреда (ущерба) субъектам экономических отношений, то ест создания эффективного механизм «регуляторной гильотины».

\section{Особенности реформ контрольно-надзорной деятельности}

К настоящему времени в России сложилась непростая ситуация. С одной стороны, власть всячески пытается поддержать развитие экономики и бизнеса, с другой - наличествует множество факторов, активно этому препятствующих. По данным Правительства, сейчас в России существует 46 контрольно-надзорных ведомств, которые проводят около 220 видов проверок. Общее число требований, описанных на тысячах страниц нормативных актов, - 2 млн норм, в числе которых со времен СССР сохранилось свыше 9 тыс. 
нормативных актов, устанавливающих обязательные требования к бизнесу при проверках. Многие из них давно устарели, соблюсти все из них не может ни один предприниматель. Такое положение в свете декларирования «российского экономического рывка» неприемлемо. Поэтому в рамках послания Президента Российской Федерации Федеральному Собранию от 15 января 2020 года Президентом поручено Правительству Российской Федерации обеспечить отмену с 1 января 2021 г. всех нормативных правовых актов, устанавливающих требования, соблюдение которых подлежит проверке при осуществлении государственного контроля (надзора), и введение в действие новых норм, содержащих актуализированные требования, разработанные с учетом риск-ориентированного подхода и современного уровня технологического развития в соответствующих сферах. ${ }^{1}$

По оценкам экспертов Организации экономического сотрудничества и развития (ОЭСР) выделяется три способа разрешения данной проблемы:

- отмена «старого» регулирования и создание новых правил. Такой способ в масштабах всей страны применить не удавалось еще никому в мире вследствие невероятных финансовых, лоббистских и когнитивных издержек;

- подготовка заинтересованными субъектами списков основополагающих проблемных правовых актов и замена их на заново созданные, что является более приемлемым способом. При этом создание таких списков будет подвергаться серьезным лоббистским усилиям со стороны отрасли и регулятора. В своем конечном результате созданные списки будут в большой степени зависеть от субъективных влияний исполнителей, результаты могут совсем не отражать решение проблемы отраслевого регулирования;

- сплошной общесистемный пересмотр регулирования. В этом случае производится пересмотр всех действующих обязательных государственных требований специально созданной структурой по установленным объективным критериям. То есть метод масштабного нормативного анализа регуляторов и пересмотр действующих нормативноправовых актов, которые будут одобрены, изменены или утратят силу.

Такой метод реформы контрольно-надзорной деятельности обозначается термином «регуляторная гильотина». Он был разработан международной консалтинговой компанией «Джейкобс, Кордова и Партнеры» (Jacobs, Cordova \& Associates) на основе удачного опыта отсечения устаревших законодательных норм в 1980-е годы в Швеции и Южной Корее. Не везде в мире применяют именно «регуляторную гильотину» в чистом виде, какие-то страны разрабатывают свои собственные механизмы. Но суть их та же - снижение административной нагрузки на бизнес для обеспечения устойчивого экономического роста.

На сегодняшний день этот структурированный процесс был применен уже более 100 странами. Опыт Австралии, Великобритании, Вьетнама, Мексики, США и Хорватии показывает, что в этих странах удалось сократить от 15 до 50 \% ненужных государственных требований в контрольно-надзорной деятельности. Это привело к тому, что бизнес сэкономил миллиарды долларов, а экономика избавилась от лишней нагрузки и стала расти намного быстрее. При этом были созданы миллионы новых рабочих мест, это способствовало повышению эффективности в борьбе с коррупцией.

Любая регуляция, необоснованная с точки зрения законности и необходимости для правительственных стратегий рыночной экономики, должна быть отменена. Любая регуляция, которая законна и необходима, но не является благоприятной для бизнеса, должна быть максимально упрощена. ${ }^{2}$

Работа по реализации концепции «регуляторной гильотины» в Российской Федерации проводится в соответствии с утвержденной Правительством Российской Федерации

${ }^{1}$ Перечень поручений по реализации Послания Президента Федеральному Собранию от 27.02.2019 г. № Пр-294.

2 Пересмотр устаревших регуляций посредством Регуляторной Гильотины. 
«дорожной картой» ${ }^{1}$ с обязательным привлечением всех заинтересованных сторон - представителей предпринимательского, экспертного, научного сообществ - с применением разработанной Методики ее исполнения ${ }^{2}$. В целях реализации (п. 2) «дорожной карты» Минэкономразвитием разработан проект Федерального закона «Об обязательных требованиях в Российской Федерации». ${ }^{3}$ Он призван определить понятие обязательного требования, а также регламентировать процесс разработки и принятия таких требований, установить цели и основные принципы их закрепления в законодательстве, обеспечить закрепление на законодательном уровне механизма отмены с 1 января 2021 года ранее действовавших обязательных требований. Также разработан проект Федерального закона «О государственном контроле (надзоре) и муниципальном контроле в Российской Федерации», ${ }^{4}$ которым предусмотрено совершенствование такой деятельности. Принятие этого законопроекта позволит создать системное процессуальное регулирование контрольно-надзорной деятельности, которое должно минимизировать административное давление на бизнес.

В целях реализации реформы Подкомиссией по совершенствованию контрольных (надзорных) и разрешительных функций федеральных органов исполнительной власти при Правительственной комиссии по проведению административной реформы ${ }^{5}$ утверждены составы 41 рабочей группы по реализации механизма «регуляторной гильотины». Деятельность рабочих групп будет направлена на участие в формировании новых структур регулирования, подготовке проектов нормативных правовых актов, содержащих обязательные требования, а также других документов в соответствующих сферах общественных отношений, негативно влияющих на общий бизнес-климат и регуляторную среду.

Результатом работы групп, ведение которой предполагается до конца 2020 года, должно стать создание новой системы контрольно-надзорного регулирования. Пересмотр предъявляемых к бизнесу обязательных требований планируется закончить к 2021 году. Установленный алгоритм работы «гильотины» состоит в том, что Правительством формируется реестр всех правовых регуляций, прямо или косвенно влияющих на бизнес, создавая тем самым базу данных правовых норм или административных процедур. Создание такого обоснованного реестра является большим прорывом в ликвидации негативного регулятивного влияния на общий бизнес-климат.

Каждая правовая норма или административная процедура должна будет пройти через фильтры и оцениваться на трех уровнях:

- государственными служащими в министерствах, высокая профессиональная деятельность которых должна быть залогом успеха;

- представителями бизнеса, как заинтересованными субъектами в ликвидации негативного регулятивного влияния на общий бизнес-климат;

- органом, который будет отвечать за реализацию «регуляторной гильотины» и принятие конкретных решений.

Включенные в конкретный процесс аналитики субъекты должны дать ответы на вопросы: имеется ли в законе необходимость регуляции; позитивна ли норма для бизнеса; необходимы и обоснованы ли финансовые выплаты, установленные этим законом.

После оценки экспертами правовой нормы или административной процедуры они распределяются в одну из трех групп: сохранить и занести в действующий реестр; упростить, после чего законодательная власть и Правительство предпримут необходимые шаги их оптимизации, упрощения запутанных нормативно-правовых актов; отменить, после че-

${ }^{1}$ План мероприятий («дорожная карта») по реализации механизма «регуляторной гильотины» от 29.05.2019 г. № 4714п-П36.

${ }^{2}$ План мероприятий («дорожной карты») по реализации механизма «регуляторной гильотины».

\footnotetext{
${ }^{3}$ https://sozd.duma.gov.ru/

${ }^{4} \mathrm{https}: / /$ sozd.duma.gov.ru/

${ }^{5}$ Распоряжение Правительства РФ от 18.09.2012 г. № 1729-р.
} 
го законодательными органами, Правительством будут сделаны необходимые шаги для устранения ненужных нормативно-правовых актов.

«Уцелевшие» оптимизированные нормы и административные процедуры, занесенные в действующий реестр, для представителей бизнеса и граждан страны будут является правовыми регуляторами экономических отношений в сфере контрольно-надзорной деятельности при ведении бизнеса.

\section{Зарубежный опыт регулятивной гильотины}

Международный опыт показывает, что количество стран, которым не удалось реализовать дерегуляционные изменения, составляют большинство по сравнению с теми странами, где удалось это сделать успешно. Несомненно, что осуществление реформы требует мощного и прозрачного политического руководства и поддержки общественности. Наиболее интересным и полезным может оказаться опыт США, где с 1993 г. действует подписанное Президентом США Правительственное распоряжение № 12866 «О планировании регулирования», в соответствии с которым проводилась реформа регулирования по улучшению качества планирования и обеспечения легитимности контрольнонадзорных мероприятий и их общественной прозрачности. С 2017 года действует подписанное Президентом США Правительственное распоряжение № 13771 «Сокращение регулирующих функций и контроль расходов на выполнение таких функций», где в целях повышения эффективности управления государственными расходами был введен принцип $2: 1$, т.е. при принятии одной новой нормы регулирования должны быть исключены две действующие нормы, при этом расходы на введение новой нормы должны полностью компенсироваться за счет отмены действующих норм. На 2018 г. уже была запланирована реализация принципа $3: 1$, т.е. отмена трех действующих норм для каждого нового регулятивного действия. В ходе первого года исполнения данного акта были отменены 244 действующие нормы, исключены из планов принятия 535 норм, перенесено на долгосрочную перспективу 700 норм, принято 67 актов по дерегулированию, принято 3 новых акта по регулятивным действиям (или 22:1) [Александров, 2019]. Вследствие этого произошел рост экономики США, где в первом квартале 2019 г. ВВП вырос на 3,1 \%, во втором - замедлился до 2,1 \% и сохранил этот показатель в третьем.

В России около 9 тыс. актов, устанавливающих обязательные требования. Сколько из них удастся изучить и после изучения представить под «гильотину» до 1 февраля 2020 г. - точно сказать никто не может. Но подготовка «дорожной карты» для работы «гильотины» на российской почве поручена аппарату Правительства. При этом результаты проведения большого объема изъятий полномочий и процедур из российского действующего правового регулирования не предсказуемы.

Например, в Южной Корее за 11 месяцев проанализировали свыше 11 тыс. актов, в Хорватии - около 1,4 тыс. Можно только надеяться, что сотрудники аппарата Правительства будут способны преодолеть бюрократические трения и борьбу за полномочия, которые неизбежно возникнут на этапе «отсекай, упрощай и сохраняй». При этом Российская Федерация - самобытная страна, поэтому есть ряд факторов, способных как принести пользу от «гильотины», но, как ни странно, и нанести вред. Важнейший фактор - определение задач для достижения цели «гильотины»- устранение лишних отраслевых нормативно-правовых актов, чтобы бизнесу стало проще работать.

\section{Регуляторная гильотина в действии}

Однако задачи регуляторной гильотины контрольно-надзорной деятельности со временем уточняются и изменяются. Например, в рамках обсуждения реформы контрольно-надзорной деятельности (КНД) над бизнесом Минтруд предложил ввести особый механизм государственного регулирования трудовых отношений, выйдя с инициативой не распространять положения реформы на трудовые отношения, а также изменить законо- 
проект о госконтроле. Это вызвано необходимостью корректировок реформы существованием рисков для работников на фоне увеличения преимуществ для работодателей, что и было подтверждено профсоюзами. Уже в апреле 2019 г. стали появляться конфликты, когда регулятор предлагал сохранить существующие правила, а отрасль - отменить. Многие ведомства пытаются добиться для себя исключений (сейчас в списке 33 министерства и ведомства, включая МВД, МЧС, Минюст, Минздрав, Минкультуры, Минприроды, Минпромторг, Минстрой, Минтранс, Минтруд, ФАС России, Роспотребнадзор). Такие исключения нарушают логику и системность проводимых реформ контрольнонадзорной деятельности. Также появляются мнения о том, что Минэкономразвития может продлить деятельность по отмене устаревших нормативных правовых актов всех уровней до 2023 года. Это связано с тем, что необходимо больше времени для проверки региональных и муниципальных норм. До 1 января 2021 г. планируется в рамках «регуляторной гильотины» завершить проверку нормативно-правовой базы федерального уровня, до 2022 г. - проверить нормы субъектов РФ, до 2023 г. - муниципальные нормы ${ }^{1}$

Необходимость процедуры доказывания при введении, изменении, сохранении государственного регулирования обусловлена объективными характеристиками субъектов процесса принятия решений и спецификой самого процесса нормотворчества. Качественное регулирование должно основываться на наилучших доступных доказательствах, включая научные и экспертные данные. Но при этом следует учитывать и то, что в рабочей группе при обсуждении правового акта может возникнуть три конкурирующие позиции: позиция регулятора, который будет отстаивать сугубо свои интересы; позиция крупного бизнеса, отстаивающего свои интересы; позиция мелкого бизнеса, для которого позиция крупного бизнеса является нежизнеспособной.

В этой связи необходимо найти рациональное решение при различных точках зрения в экспертном сообществе. В этом случае необходима четко установленная процедура преодоления лоббистских устремлений в сторону государственного интереса. Эта ситуация может быть рассмотрена с принятием решения на «специальной согласительной» комиссии.

Также следует отметить решения рабочих групп различных отраслей по пересекающимся контрольно-надзорным полномочиям, когда по одному и тому же правовому акту при рассмотрении разными рабочими группами принимаются не совпадающие решения. В этой связи необходимо окончательное «надгрупповое» решение. Также следует обратить внимание на то, что под видом новых требований могут появиться старые правила вследствие лоббистских усилий со стороны отрасли и регулятора, а также на отсутствие объективных критериев пересмотра правовых регуляций, прямо или косвенно влияющих на бизнес, что может негативно повлиять на результаты реформы.

Реализация механизма «регуляторной гильотины» обусловливает необходимость оценки регулирующего воздействия (OPB) как одного из важнейших инструментов диалога власти и бизнеса для выработки эффективной государственной политики, что стимулирует органы-разработчики тщательно продумывать свои решения. Причины популярности института оценки регулирующего воздействия определяются особым правовым механизмом обсуждения проектов нормативных правовых актов, затрагивающих интересы бизнеса и инвесторов, до момента их вступления в силу [Арзамасов, 2013]. Также предполагается анализ социальных и экономических последствий принятия нормативного правового акта. В этом случае «насаждение сверху» таких правовых норм при использовании правил ОРВ невозможно.

Главную опасность для эффективной реализации механизма «регуляторной гильотины» несет коррупция в органах государственной власти и местного самоуправления.

${ }^{1}$ «Регуляторную гильотину» могут продлить до 2023 года. https://www.business.ru /news /12027-regulyatornuyu-gilotinu-mogut-prodlit-do-2023-goda 
Отмена нормативных актов, особенно ГОСТов на промышленные изделия, продукты, в том числе и экологические, создает для человека затруднения в принятии решений и пользовании товаром. Отмену большого количества нормативных документов и ГОСТов нельзя компенсировать и возместить очень быстро. В этом случае возникнет правовой вакуум, а в таком правовом вакууме будут действовать и уже действуют коррупционные связи. Если говорить о российской коррупции, то она серьезно затрудняет нормальное функционирование всех государственных структур, препятствует проведению социальных преобразований и повышению эффективности национальной экономики, вызывает в российском обществе тревогу и недоверие к государственным институтам, в том числе и в вопросе реализации механизма «регуляторной гильотины».

\section{Заключение}

Следует констатировать, что процесс реализации контрольно-надзорной реформы зависит от способности экспертного сообщества, рабочих групп и регулятивных органов обеспечить качественное и оперативное выполнение поставленных задач под руководством Минюста. Но это только часть реформы государственного управления, основные сложности еще впереди. Следует согласиться с тем, что работу, проведенную в период административной реформы, требуется не просто провести заново, а поставить «на поток», создать механизм постоянного контроля за возникающими и перераспределяемыми полномочиями ${ }^{1}$. От того, как пройдет этап контрольно-надзорной реформы, будет зависеть эффективность системы российского государственного управления.

\section{Список литературы}

1. Аганина Р.Н., Андронова Т.А. 2020. Модернизация института государственного контроля предпринимательской деятельности. Право и политика. № 2. С. 36-47.

2. Александров О.В. 2019. «Регуляторные гильотины»: международный опыт устранения препятствий для бизнеса и инвестирования». Торговая политика. Trade policy. № 1/17. C. 107-118.

3. Арзамасов Ю.Г. 2013. Оценка регулирующего воздействия: понятие, функции, проблемы институализации. Право и образование. № 11. С. 4-17.

4. Кармолицкий А.А. 2014. К вопросу об административном надзоре в сфере исполнительной власти. Законодательство. № 1. С. 48-58.

5. Кнутов А.В. 2015. Обязательные требования к хозяйственной деятельности в России. Вопросы государственного и муниципального управления. № 1. С. 104-123.

6. Любимов Ю., Новак Д., Цыганков Д., Нестеренко А., Варварин А., Ибрагимов Р., Жаркова О., Москвитин О., Маслова Н., Верле Е. 2019. Регуляторная гильотина. Закон. № 2. C. 20-36.

7. Майоров В.И. 2019. Модернизация системы контроля и надзора: новая регуляторная политика. Административное право и процесс. № 11. С. 34-36.

8. Регуляторная политика в России: основные тенденции и архитектура будущего. А.Е. Голодникова, А.А. Ефремов, Д.В. Соболь. Москва: Центр стратегических разработок, 2018. $192 \mathrm{c}$.

9. Семенов С.В., Чаплинский А.В. 2014. О совершенствовании правового регулирования системы государственного и муниципального контроля в России. Вопросы государственного и муниципального управления. № 4. С. 118-135.

10. Синдеева И.Ю. 2014. Ответственность органов исполнительной власти при осуществлении государственного контроля. Государственная служба. № 5. С. 6-11.

11. Хачатуров А. Надзор на отсечение. URL: https://novayagazeta.ru/authors/45237 (дата обращения 20.01.2020 г.).

${ }^{1}$ Татьяна Нестеренко: без сокращения госслужащих не будет и повышения зарплат [элект pec] https://ria.ru/20190923/1558915623.html 
12. Щербатова С. 2019. Коснется ли "регуляторная гильотина" саморегулируемых организаций, выдающих компаниям допуски к производству работ в области строительства? Жилищное право. № 6. С. 5-16.

\section{References}

1. Aganina R.N., Andronova T.A. 2020. Modernization of the institute of state control of entrepreneurial activity. Law and Politics, 2:36-47.

2. Alexandrov O.V. 2019. "Regulatory Guillotines": International Experience in Removing Barriers to Business and Investment." Trade policy. Trade policy, 1/17: 107-118.

3. Arzamasov Yu.G. 2013. Regulatory impact assessment: concept, functions, problems of institutionalization. Law and education, 11: 4-17.

4. Karmolitsky A.A. 2014. To the question of administrative supervision in the field of executive power. Legislation, 1: 48-58.

5. Knutov A.V. 2015. Mandatory requirements for economic activity in Russia. Questions of state and municipal government, 1: 104-123.

6. Lyubimov Yu., Novak D., Tsygankov D., Nesterenko A., Varvarin A., Ibragimov R., Zharkova O., Moskvitin O., Maslova N., Verle E. 2019. Regulatory guillotine. Law, 2: 20-36.

7. Mayorov V.I. 2019. Modernization of the control and supervision system: a new regulatory policy. Administrative law and process, 11: 34-36.

8. Regulatory policy in Russia: main trends and architecture of the future. 2018. Ed. A.E. Golodnikova, A.A. Efremov, D.V. Sable [et al.]. Moscow, Center for Strategic Research, 192 p.

9. Semenov S.V., Chaplinsky A.V. 2014. On improving the legal regulation of the state and municipal control system in Russia. Issues of state and municipal government, 4: 118-135.

10. Sindeeva I.Yu. 2014. Responsibility of executive authorities in the exercise of state control. State service, 5: 6-11.

11. Khachaturov A. Surveillance for clipping. URL: https://novayagazeta.ru/authors/45237 (date of appeal 01/20/2020).

12. Shcherbatova S. 2019. Will the "regulatory guillotine" affect self-regulatory organizations that issue companies approvals for construction work? Housing law, 6: 5-16; Administrative law, 3: $57-62$.

\section{Ссылка для цитирования статьи For citation}

Чепунов О.И. 2020. Некоторые проблемы «регуляторной гильотины». NOMOTHETIKA: Философия. Социология. Право. 45 (1): 133-140.

DOI 10.18413/2712-746X-2020-45-1-133-140

Chepunov O.I. 2020. Some problems of the «regulatory guillotine». NOMOTHETIKA:

Philosophy. Sociology. Law. 45 (1): 123-130 (in Russian). DOI 10.18413/2712-746X-2020-45-1-133-140 